\title{
More Harm than Good? Cannabis, Harm and the Misuse of Drugs Act
}

Gary R. Potter, Lancaster University Law School

Hattie Wells, Independent Drug Researcher

\begin{abstract}
Purpose: To consider the nature of cannabis-related harms under the United Kingdom's Misuse of Drugs Act (MDA). Written for the specific context of this four-paper special section on 50 years of the MDA, it argues that the MDA may cause more harm than it prevents.

Design/methodology/approach: An opinion piece offering a structured overview of cannabis-related harms under prohibition. It summarises existing evidence of the ways in which prohibition may exacerbate existing - and create new - harms related to the production, distribution, use and control of cannabis.
\end{abstract}

Findings: The paper argues that prohibition of cannabis under the MDA may cause more harm than it prevents.

Originality: It has long been argued that the MDA does not accurately or fairly reflect the harms of the substances it prohibits, and much existing research points to different ways in which drug prohibition can itself be harmful. The originality of this paper lies in bringing together these arguments and developing a framework for analysing the contribution of prohibition to drug-related harm.

Key words: Harm, Prohibition, Cannabis, Misuse of Drugs Act, Harm Reduction

Article Classification: Policy Paper.

Category: Viewpoint Paper.

\section{Introduction: drug policy and harm}

One justification for prohibition of drugs is that they are harmful. There are other justifications, and prohibition may be better understood through perspectives of ideological censure, control, legal moralism or legal paternalism (see, e.g., MacCoun and Reuter, 2001). But harm prevention is inherent to the UK's 1971 Misuse of Drugs Act (MDA), which the introductory text describes as "[a]n act to make new provision with respect to dangerous or otherwise harmful drugs". This paper focuses on this harm prevention dimension of the MDA - whether naïve or not to take this claimed justification of harm prevention in drug policy at face value, it seems reasonable to hope that any area of public policy aims for - and succeeds in - reducing harm to the public at large.

It is accepted that drug prohibition can and does cause some harm itself, through limiting individual freedoms to consume drugs and through the imposition of punishment on those who break the law. The justification for imposing such harms under the law is that prohibition prevents more harm than it causes through deterring use. This position is succinctly expressed by DuPont and Voth (1995 p.461): "A restrictive drug policy is a deterrent to drug use and helps reduce drug-related costs and 
societal problems. Although legalization or decriminalization of drugs might reduce some of the legal consequences of drug use, increased drug use would result in harmful consequences."

The logic of this position implies a utilitarian calculus: the amount of drug-related harm is dependent on the number of users; fewer users means less total harm. However, the calculation is more complicated than that. Fewer users undoubtedly means fewer people exposed to the individual harms related to drug use. But if the severity of those harms is increased because of prohibition then the total amount of harm to users may increase even if the number of users is reduced. And there is an assumption here that prohibition has a significant impact on the number of people using drugs: if it does not, then increased harm to users more readily becomes an increase in overall harm. Further, a calculation of total harms related to drugs should also consider harms to others: if prohibition increases these harms, prohibition on the grounds of harm prevention becomes even harder to justify.

Numerous reports, from academics (e.g., Nutt et al., 2010), charities (e.g., RSA 2007), criminal justice agencies (e.g., Runciman, 2000) and official government bodies (e.g., ACMD, 2002), have argued that cannabis (and, in some cases, other drugs) are mis-categorised under the MDA in relation to its harmfulness as a substance. This paper does not seek to revisit the argument of the relative harm of cannabis compared to other drugs or its classification under the MDA. Instead, it seeks to overview the broader argument that prohibition of cannabis causes more harm than it prevents.

The paper supports this argument by identifying the ways in which drug policy may exacerbate, rather than prevent, both individual and societal cannabis-related harms. It focuses on cannabis, as the most widely used illegal drug in the UK - and one for which the inherent harms are small (at least in comparison to other illegal - and legal - drugs) (Nutt et al., 2010) and, arguably, the harms caused by drug policy are most pronounced. However, a similar analytical framework can be applied to other prohibited drugs - and while the specific calculus will vary for different substances, the conclusion is likely to be the same: under prohibition, drug-related harms have been increased rather than reduced.

The paper takes the form of a structured overview of different aspects of cannabis-related harms under prohibition. There is a vast literature to draw on, and the paper is necessarily selective. As such, it aims to be indicative rather than exhaustive - both of the range of harms considered and the literature consulted. Literature cited prioritises existing reviews of evidence in the different areas discussed. Reflecting both the limits of space, and the remit of this special section (to critique the MDA on its $50^{\text {th }}$ anniversary) and the paper itself (a viewpoint paper), literature is also selected to outline the range and nature of the arguments rather than fully assess the evidence base for each of those arguments. There is much literature (some of it cited here) that does explore the individual arguments in more depth, and more evidence is amassing on how legalisation of cannabis (e.g., in Uruguay, Canada and a growing number of individual US states) changes its harmfulness. The central aim of the current paper is to try to bring the various arguments together in one article, structured under the categories of harms related to cannabis use, to production and distribution, and to law enforcement, considering which harms are inherent to cannabis and which are created or exacerbated by prohibition.

\section{Cannabis demand and supply under the MDA}

The 2019-20 sweep of the Crime Survey for England and Wales (ONS, 2020) found that $31.1 \%$ of $16-$ 59-year-olds reported having ever used cannabis, a figure that has remained remarkably steady across the last 20 years. Last-year use was reported by $7.8 \%$ of the population, a decline from the $10.7 \%$ peak reported in $2002-03$, but a continuation of a steady increase from the low-point $6.3 \%$ of 
2012-13. Comparable figures do not exist for before the 1990s, but cannabis use expanded significantly across the second half of the $20^{\text {th }}$ Century - despite the introduction of the MDA (Abrams, 2008). With 2.6 million annual users 50 years after its introduction, it seems the MDA has had limited deterrent effect.

Demand is predominantly from 'recreational' users, but increasingly includes medical users (Nutt, 2014; APPG 2016). The expansion of medical use is fuelled, at least in part, by accumulated evidence of the beneficial effects of cannabis for a range of medical conditions - and the legalisation of medical cannabis in an increasing number of countries. Technically, cannabis was legalised for medical use in the UK in November 2018. In reality, the number of people with access to legallyprescribed medical cannabis is tiny (Bone and Potter, 2021). Whether using for medical or recreational purposes, demand persists despite criminalisation and depends on illegal production and supply.

The UK cannabis market has been valued at over $£ 2.5$ billion per annum (Snowdon, 2018). This lucrative market is largely in the hands of criminals incentivised by profit, although there has been a significant increase in small-scale cultivation by users looking to be self-sufficient and, in many cases, to supply small groups of friends and acquaintances without depending on the criminal market (Potter and Klein, 2020). In either case, under prohibition, production and supply remain entirely unregulated - a situation conducive to the creation rather than the prevention of harm.

\section{Harms related to cannabis under prohibition}

As with all drugs, cannabis is linked to a wide range of harms. Consumption poses risks to physical and mental health, and may also have negative impacts on users' social and economic well-being. Other purported risks include developing dependency or addiction, and escalation to use of more harmful drugs. Cannabis markets are often linked to serious and organised crime, which harms society in a variety of ways. Importation of cannabis depends on overseas production, often linked to environmental harms and political instability in producer nations. Domestic cultivation carries its own environmental and situational risks, and can result in produce that increases the risks related to consumption. Further harms to society relate to the enforcement of prohibition, including: the demands placed on criminal justice and health services; the criminalisation, stigmatisation and alienation of the significant proportion of the population that uses cannabis; and the loss of potential health, economic and other benefits that could be realised if cannabis were legal. The following sections overview these harms in more detail, focusing particularly on how prohibition exacerbates the (few) harms that are inherent to cannabis itself and generates harms that would not otherwise exist.

\section{Harms related to cannabis use}

\section{Death and physical health problems}

Preventing deaths is a strong justification for prohibition, but there is little evidence that the MDA prevents deaths from cannabis use. Unlike many other illegal (and legal) drugs, cannabis carries no risk of death by overdose (Nutt et al., 2010). There is some risk of death or serious harm (to users or to others) related to behaviour under the influence of cannabis: cannabis intoxication increases the risk of accident when driving (Sewell et al., 2009). However, increased prevalence of cannabis use need not mean increased prevalence of cannabis-related accidents (Ayedotte et al., 2017). Prohibition is neither a useful nor necessary tool for preventing deaths related to drug-impaired driving: drug-impaired driving and similar dangerous driving behaviour are crimes independent of prohibition under the MDA. 
Acute risks aside, cannabis has been linked to a range of adverse health effects (Volkow et al., 2014). This includes respiratory illnesses and cardiovascular problems (Gates et al., 2014; Ribeiro and Ind, 2016; Nugent et al., 2017; National Academies of Science, Engineering and Medicine, 2017). However, the relationship appears more associated with the route of administration than inherent to cannabis itself (Russell et al., 2017). Smoking cannabis, especially if mixed with tobacco, is the most harmful route of administration. Prohibition arguably acts as a barrier to encouraging less harmful modes of consumption, although the declining popularity of tobacco smoking should help break the link between cannabis and tobacco.

\section{Mental health and addiction}

The link between cannabis and mental health problems has been of more concern in UK political discourse. Cannabis use has been shown to correlate with schizophrenia and other psychotic disorders (Manrique-Garcia et al., 2012; Moore et al., 2007) although causation is hard to establish (ACMD, 2008). Cannabis use does increase the risk of psychosis, especially among younger users, but the absolute risk remains extremely low (Hickman et al., 2009). Although cannabis is not associated with addiction in the same way that heroin, crack-cocaine, tobacco or alcohol are (Nutt et al., 2010), there has been an upsurge in cannabis users seeking treatment for problematic use (McCulloch, 2017).

The risks of mental health problems and addiction, where they do occur, have been largely attributed to the effects of tetrahydrocannabinol (THC, the main psychoactive component of cannabis) (Ranganathan and D'Souza, 2006; Morgan et al., 2010; Di Forti et al., 2009; Hall, 2009). Other cannabinoids mitigate these effects. Specifically, cannabidiol (CBD) has been demonstrated to have neuro-protective, anxiolytic and antipsychotic effects (Englund et al., 2013; Englund et al., 2014; Morgan et al., 2010; Morgan and Curran, 2008; Fakhoury 2016). Prohibition makes it impossible to regulate to ensure a lower-risk substance, and leaves users with no way of knowing the potency of what they are consuming. In countries where cannabis is available legally, it has been possible to introduce maximum and minimum THC and CBD limits (Transform, 2018) and clear labelling on cannabis products (Klieger et al., 2017).

\section{Other drug use and criminal behaviour}

A concern often raised in support of prohibition is that cannabis presents a 'gateway' to using other, more harmful drugs. The idea that cannabis inevitably leads to the use of harder drugs has long been refuted (Zimmer and Morgan, 1997). Where there is a potential gateway effect, this relates more to overlapping markets than any psychopharmacological factors (Uhl and Krauss, 2009; Melberg et al., 2009). This link is a direct result of prohibition. Breaking the link between 'soft' and 'hard' drug use is a key rationale behind the Dutch coffeeshop system. In the Netherlands, cannabis use may be higher than it is in the UK, but it is lower than many neighbouring European countries that do not have coffeeshops (Transform, 2018) and has had measurable success in separating hard and soft drug markets (Wouters and Korf, 2009).

Drug use is often associated with criminal behaviour, which may be harmful to users themselves but also causes harm to others. The relationship is complex: it can include crimes committed by users while under the influence of drugs (psychopharmacological crimes), those committed to fund drug use (economic-compulsive crimes), and those occurring in relation to the operation of drug markets (systemic crimes) (Goldstein, 1985). However, these links are most evident for drugs such as heroin and crack-cocaine, and the drug most associated with psychopharmacological crime is alcohol 
(Bennet and Holloway, 2005). Cannabis users have been found to be no more involved in crime than non-users (Pedersen and Skardhamar, 2010).

\section{Harms related to production and distribution}

Cannabis markets around the world have undergone significant change in recent decades (Decorte et al., 2011). Domestic cultivation has replaced importation as the dominant source of cannabis (Potter and Klein, 2020). Indoor growing, utilising high-tech cultivation techniques, is linked to potentially more harmful cannabis products and generates environmental and situational harms and risks. The portion of the market that is still served by importation is linked to environmental damage and political instability in producer nations (UNODC, 2021). Commercial-scale cultivation and importation is facilitated by groups involved in other drug markets and in serious and organised crime. Prohibition provides these criminal networks with a significant source of revenue.

For reasons of space, and reflecting the fact that domestic production now accounts for the majority of cannabis consumed in the UK, the discussion in this section will focus on harms associated with production and distribution within the UK.

\section{Harmful products}

The general trend amongst illegal cannabis producers has been to prioritise increasing THC levels, while breeding out (deliberately or inadvertently) neuroprotective cannabinoids such as CBD (Potter et al., 2018). This results in a stronger product that can bring in greater profit, but exposes users to greater levels of the potency-related risks outlined above. Some cannabis growers use chemical fertilizers, pesticides, plant growth regulators and other products, many of which are not subject to the same level of regulation that would apply to products explicitly marketed for agricultural crops intended for human consumption (Subritzky et al., 2017; Lenton et al., 2018). Illegal producers and suppliers have also been reported to adulterate herbal cannabis with hairspray or glass beads to make it appear to be of a higher quality or weight (Randerson, 2007). Adulterated produce generates health risks that are not inherent in cannabis itself. Under prohibition, it is impossible to regulate growing practices or to monitor product quality - whether in relation to potency or purity.

\section{Environmental and situational harms}

Indoor production commonly employs high-tech methods including artificial lighting and automated irrigation systems (Potter, 2010). Commercial cannabis growing often involves illegal bypassing of electricity meters. Risks include fires and floods (Potter and Klein, 2020), which can cause serious property damage. Electricity theft results in loss of revenue to electricity suppliers, a cost passed on to ordinary consumers in the form of higher prices (OFGEM, 2014).

Disposal of paraphernalia and of residual plant material can also be an environmental problem at a local level, with growers more likely to engage in fly-tipping than taking such materials to municipal waste sites (Potter and Klein, 2020). Indoor cultivation may also contribute to environmental harms more broadly, both through contribution to greenhouse gases from energy consumption and the release of volatile organic compounds into the immediate environment (Ashworth and Vizuete, 2017).

\section{Links to serious and organised crime}

Criminal groups involved in cultivation, importation or distribution of cannabis may be involved in other drug trafficking and organised crime. Such organisations are also far more likely to engage in other criminal behaviour as part of their business practice, including violence and corruption. A 
Belgian study into harms associated with cannabis cultivation found "limited harms generated" overall, and that most harms that do exist are "generated by large-scale growers" (Paoli et al., 2015 p.277).

An important example here is the use of people-trafficking and forced labour. The UK's Counter Human Trafficking Bureau estimated that some 3,000 Vietnamese children have been trafficked to Britain to serve as slave labour for criminal organisations involved in drug trafficking and cannabis production (Kelley and McNamara, 2015). While forced labour among illegal immigrants is an issue that also affects the legal agricultural industry, it becomes even harder to tackle within an industry that is operating underground.

Prohibition, instead of eliminating the cannabis market, simply leaves it in the hands of criminal enterprises. The more supply is curbed, the more valuable the illegal product becomes, and the greater the potential profits - and the incentives for others to enter the market. Evidence from the Americas suggests that legalised medical cannabis markets across the US have undermined organised crime related to drug trafficking from Mexico, reducing violence and gang-related crime on both sides of the border (Gavrilova et al., 2017).

The growth of domestic cultivation has also been associated with increased theft and violence targeting growers, where criminal groups seek to eliminate or intimidate rivals or see small-scale growers as targets. Stolen cannabis (and equipment) can be sold, and thieves calculate that their victims may not report crimes to the police for fear of being prosecuted themselves. In some cases, these small-scale growers retaliate with their own criminal activity, further escalating the amount of crime associated with growing (Potter and Klein, 2020).

\section{Harms related to law enforcement}

Enforcement of the MDA causes harm to those who are arrested, prosecuted and punished. Unequal and inconsistent application of the law exacerbates existing inequalities and undermines the legitimacy of the law more broadly. Further harms related to law enforcement include the loss of benefits that could be realised if cannabis were legal, including potential tax revenues and medical benefits.

\section{Criminalisation}

Cannabis possession accounted for $75 \%$ of all drug offences in England and Wales in 2016/17 (Allen, 2018). While these offences have mainly resulted in warnings, fixed penalty notices and cautions, significant numbers are still prosecuted for cannabis possession (Shiner et al., 2018). More serious or multiple offences can lead to more significant criminal penalties, with associated court and prison costs. Supply offences, and the heavier penalties attached to them, can affect people who grow and distribute cannabis on a small-scale, 'social supply' (Potter, 2009), basis, including those growing to supply themselves or others for medical use, as well as those who deal cannabis for financial gain.

Individuals prosecuted for cannabis offences face a range of negative consequences, extending beyond the punishment itself and damaging society at large. Even relatively mild sanctions such as official cautions result in a criminal record, which can have strongly negative consequences for future employment opportunities, finance and housing. More serious punishments, such as imprisonment, severely disrupt education and employment, and can cause or exacerbate mental health problems. Imprisonment, in effect, also punishes the families of convicted drug users; children grow up without parents, and households are forced into poverty by the loss of income. 
These negative consequences for drug users may be viewed as fitting punishments for criminals. It is therefore worth reminding ourselves what the ostensible purpose of drug law is: to minimise the harms caused by drugs to drug users, their families, and society as a whole. Prohibition attempts to achieve this, but if drug laws were enforced to the letter, every cannabis user in the country would face a more significant threat to their livelihoods and mental health from law enforcement than they would from cannabis itself. Unequal enforcement of the law avoids this scenario, but exacerbates social inequities facing those groups that are more likely to face criminal justice interventions for their cannabis use - and undermines respect for the law and the criminal justice system more generally. While the health, economic and societal consequences of cannabis use should not be ignored, they pale in comparison to the many economic and societal consequences of criminalisation.

\section{Unequal enforcement}

The vast majority of cannabis users (and those involved in cultivation and supply) never experience arrest. On one reading, this is clearly a good thing: processing 2.6 million annual offenders would clog up the criminal justice system - and have a significant impact on the functioning of society at large. However, the fact that only a small proportion of all cannabis offenders experience criminal justice intervention generates different problems. Those that are arrested are not a random sample of all cannabis offenders. Enforcement is unequal, and disproportionately falls on certain sections of society - often mirroring (and reinforcing) pre-existing social inequalities. Enforcement of cannabisrelated offences vary hugely across the UK (Allen and Kirk-Wade, 2020), and are generally higher in poorer parts of the country. Chances of arrest and punishment are significantly higher for BAME groups than for white users (Shiner et al., 2018).

\section{Enforcement and criminal justice system costs}

Cannabis user detection, arrests, and prosecutions are a significant drain on police time and resources. Formal criminal sanctions, especially imprisonment, place an additional burden on the criminal justice system. A cost-benefit analysis of the cannabis market in 2013 estimated that a legally regulated cannabis market could bring about a net benefit of $£ 280-460$ million yearly, based on estimates of the police, court and detention costs that would be saved (Bryan et al., 2015).

Various British police forces consider the resources expended on cannabis policing as unacceptably high considering the relatively minor negative consequences of cannabis use compared to other crime. A trend towards de facto decriminalisation is appearing across the UK, with police forces including Durham, Avon and Somerset, Derbyshire, Dorset and Surrey announcing reduced efforts in targeting possession or growing of cannabis for personal use in recent years (Evans, 2015; Murphy, 2016).

\section{Lost benefits}

The cannabis industry, if brought into the legal economy, could generate significant wealth and employment opportunities. A regulated cannabis market would enable the government to tax cannabis products and related industries. The Institute for Economic Affairs (IEA) estimated the potential tax revenue from this as exceeding $f 1$ billion p.a. (Snowdon, 2018), with other recent estimates ranging from $f 0.9$ billion (Bryan et al., 2015) to $f 3$ billion (Parey and Rasul, 2020). These economic benefits would come on top of the savings in criminal justice costs associated with enforcement. 
The has been a renewed interest in the medical benefits of cannabis in recent years, and over 40 countries around the world have legalised cannabis for medical purposes. The range of conditions for which cannabis may be beneficial and the scientific research into medical use are too vast to review here, but it has been estimated that over a million people in the UK could benefit if medical cannabis were legally available (APPG, 2016). Medical cannabis would not only benefit many sick people directly, it could also reduce current burdens on the NHS. Many people use, grow and supply cannabis for medical purposes despite prohibition, preferring the risk of arrest and punishment to ongoing pain and suffering (Klein and Potter, 2018). The harms associated with criminalisation seem particularly cruel when applied to people who are already sick. Ironically, as we have seen, those who become growers or suppliers of medical cannabis to others increase their own criminal involvement (and, hence, risk of more serious punishment) and expose themselves to the risk of being victimised by criminals (Potter and Klein, 2020).

Finally, the lost benefits of recreational use should not be overlooked. For many people, cannabis use is a pleasurable pastime which enhances well-being and socialising. Other reported benefits from recreational use include aiding creativity, enhancing sensory experiences, and promoting emotional, psychological and spiritual well-being. The prohibition of cannabis denies users the right to legally modulate their conscious state for recreational and other purposes. This might be justifiable in the case of an overriding public health risk, but as discussion above shows, the harms and risks of cannabis use do not clearly meet this standard. The pleasures of recreational cannabis use therefore represent a significant lost benefit to users.

In addition, there is evidence that legalising cannabis would decrease the use of both legal recreational drugs such as alcohol, and the illicit recreational use of prescription drugs such as opioids (Reiman, 2009; Kilmer and Smart, 2018; Boehnke et al., 2016). This could result in a net benefit to public health, due to the higher risk profile of these currently legal substances.

\section{Summary and conclusions}

After 50 years of the MDA, cannabis use remains widespread: prohibition has not been successful in limiting use. And it is clearly arguable that the MDA has contributed to an increase rather than a reduction in cannabis-related harms. There are few harms intrinsic to cannabis itself; physical, mental-health and social harms linked to its use relate more to mode of consumption, and the potency and purity of cannabis used. Prohibition arguably impacts on the ability to encourage safer methods of use. Leaving production and supply unregulated contributes to more harmful products appearing on the market in the form of increased potency and greater exposure to dangerous additives and adulterants. Leaving the market in the hands of profit-seeking criminals exacerbates these problems and contributes to the social harms related to serious and organised crime.

Meanwhile, where cannabis users (including medical users) turn to home-cultivation and socialsupply to avoid contact with the illegal market and to improve control over product quality they become exposed to greater risks. Production and supply are both more serious offences than cannabis possession, thus increasing the chance of receiving more serious sanctions. Self-, socialand medical-supply growers also face an increased risk of becoming victims of crime.

Imposition of criminal penalties can lead to life-long harms stemming from the stigma of a criminal record beyond the immediate harms of punishment itself. This seems particularly problematic when applied to otherwise law-abiding citizens - and even more so when applied to those using cannabis to treat (often painful and debilitating) medical conditions. Law enforcement also carries a large economic cost. Conversely, the failure to enforce the law in the majority of cases causes different 
problems, exacerbating social inequalities and undermining the legitimacy of the criminal justice system and law enforcement more generally.

Instead of reducing the risks involved with cannabis consumption, prohibition increases them. Young and vulnerable users are not protected - an illegal market carries no age restrictions. Heavy use is neither effectively discouraged nor restricted, and stigma may prevent people seeking help when it is needed. Cannabis products cannot be regulated to improve their safety; criminal producers are motivated to make them as potent and profitable as possible, often contrary to consumer preference.

Finally, in outlawing cannabis, governments fail to capitalize on potential benefits to users and society. Recreational use, as well as medical use, can be greatly beneficial to individuals. The wealth creation, job creation, and tax revenue opportunities of a legal cannabis industry are forgone.

It is established in both UK drug policy itself (HM Government, 2017) and governmental (ACMD, 2010; MacDonald et al., 2005) and academic (Nutt et al., 2010; Ritter, 2009) discourse on drug policy that any analysis of drug-related harm needs to account for harms to users and harms to society. Under such calculations, it has repeatedly been argued that cannabis is not harmful enough to justify its status as a Class B controlled drug (ACMD 2008; Nutt et al., 2010). Such analysis should consider not just the harms inherent in the production, distribution and use of cannabis, but also the harms caused by drug policy itself. Doing so adds to the argument for legalisation: if prohibition is justified by preventing drug-related harms, but causes more harm than it prevents, this is self-evidently problematic.

\section{References}

Abrams, S. (2008), "Soma, the Wootton Report and cannabis law reform in Britain during the 1960s and 1970s" In Rödner Sznitman, S., Olsson, B., and Room, R. (Ed.s), A cannabis reader: global issues and local experiences, EMCDDA, Lisbon, pp.39-50.

ACMD [The Advisory Council on the Misuse of Drugs] (2002), The classification of cannabis under the Misuse of Drugs Act 1971

ACMD [The Advisory Council on the Misuse of Drugs] (2008), Cannabis: classification and public health, Home Office, London.

ACMD [The Advisory Council on the Misuse of Drugs] (2010), Consideration of the use of multicriteria decision analysis in drug harm decision making, Home Office, London.

Allen, G. (2018), Drug seizures and offending: social indicators page, House of Commons Library, London.

Allen, G. and Kirk-Wade, E. (2020), Drug crime: statistics for England and Wales, House of Commons Library, London.

APPG [All Party Parliamentary Group for Drug Policy Reform] (2016), Access to medicinal cannabis: meeting patient needs, APPG, London.

Ashworth, K. and Vizuete, W. (2017), "High time to assess the environmental impacts of cannabis cultivation", Environmental Science \& Technology 51, 2531-2533.

https://doi.org/10.1021/acs.est.6b06343 
Aydelotte, J., Brown, L., Luftman, K., Mardock, A., Teixeira, P., Coopwood, B. and Brown, C. (2017), "Crash fatality rates after recreational marijuana legalization in Washington and Colorado", American Journal of Public Health 107, 1329-1331. doi:10.2105/AJPH.2017.303848

Bennett, T. and Holloway, K. (2005), Understanding drugs, alcohol and crime. Open University Press, Maidenhead.

Boehnke, K.F., Litinas, E. and Clauw, D.J. (2016), "Medical cannabis use is associated with decreased opiate medication use in a retrospective cross-sectional survey of patients with chronic pain", Journal of Pain 17, 739-744. https://doi.org/10.1016/j.jpain.2016.03.002

Bone, M. and Potter, G.R. (2021), "Medical Cannabis in the UK: the (false) dawn of a new era?" In Corva, D. and Meisel, J. (Ed.s), The Routledge handbook of post-prohibition cannabis research, Routledge, Philadelphia.

Bryan, M., Del Bono, E. and Pudney, S. (2015), Licensing and regulation of the cannabis market in England and Wales: towards a cost-benefit analysis, Beckley Foundation, Oxford.

Decorte, T., Potter, G.R. and Bouchard, M. (Ed.s) (2011), World wide weed: global trends in cannabis cultivation and control, Ashgate, Aldershot.

Di Forti, M., Morgan, C., Dazzan, P., Pariante, C., Mondelli, V., Marques, T.R., ... Murray, R.M. (2009), "High-potency cannabis and the risk of psychosis", British Journal of Psychiatry 195(6), 488-91. https://doi.org/10.1192/bjp.bp.109.064220

DuPont, R.L. and Voth, E.A. (1995), "Drug legalization, harm reduction, and drug policy", Annals of Internal Medicine 123(6), 461-465. https://doi.org/10.7326/0003-4819-123-6-199509150-00011

Englund, A., Morrison, P., Atakan, Z., Kralj, A., Stone, J.M., Nottage, J. and Murray, R. (2014), "'The good, the bad, and the ugly': Experimental human studies of CBD, THC, and THCV", Schizophrenia Research 153(1), S32. https://doi.org/10.1016/S0920-9964(14)70108-2

Englund, A., Morrison, P., Nottage, J., Hague, D., Kane, F., Bonaccorso, S., ... Feilding, A. (2013), "Cannabidiol inhibits THC-elicited paranoid symptoms and hippocampal-dependent memory impairment", Journal of Psychopharmacology 27(1), 19-27.

https://doi.org/10.1177/0269881112460109

Evans, M. (2015), "Police force gives cannabis users green light to grow drugs", The Telegraph, 21 July 2015.

Fakhoury, M. (2016), “Could cannabidiol be used as an alternative to antipsychotics?" Journal of Psychiatric Research 80, 14-21. https://doi.org/10.1016/j.jpsychires.2016.05.013

Gates, P., Jaffe, A. and Copeland, J. (2014), "Cannabis smoking and respiratory health: consideration of the literature", Respirology 19, 655-662. https://doi.org/10.1111/resp.12298

Gavrilova, E. Kamada, T. and Zoutman, F. (2017), "Is legal pot crippling Mexican drug trafficking organisations? The effect of medical marijuana laws on US crime", Economic Journal 129(617), 375407. https://doi.org/10.1111/ecoj.12521

Goldstein, P. (1985), "The drugs/violence nexus: a tripartite conceptual framework", Journal of Drug Issues 39, 143-174. https://doi.org/10.1177/002204268501500406 
Hall, W. (2009), "The adverse health effects of cannabis use: what are they, and what are their implications for policy?", International Journal of Drug Policy 20(6), 458-466.

https://doi.org/10.1016/j.drugpo.2009.02.013

Hickman, M., Vickerman, P., Macleod, J., Lewis, G., Zammit, S., Kirkbride, J., and Jones, P. (2009), "If cannabis caused schizophrenia-how many cannabis users may need to be prevented in order to prevent one case of schizophrenia? England and Wales calculations", Addiction 104, 1856-1861. http://dx.doi.org/10.1111/j.1360-0443.2009.02736.x

Hill, M.N. (2014), "Clearing the smoke: what do we know about adolescent cannabis use and schizophrenia?" Journal of Psychiatry and Neuroscience 39(2), 75-77. doi:10.1503/jpn.140028

HM Government (2017), 2017 Drug Strategy, HM Government, London.

https://assets.publishing.service.gov.uk/government/uploads/system/uploads/attachment_data/file /628148/Drug_strategy_2017.PDF

Kelley, A. and McNamara, M.-L. (2015), “3,000 children enslaved in Britain after being trafficked from Vietnam", The Guardian 23 May 2015.

Klieger, S.B., Gutman, A., Allen, L., Pacula, R.L., Ibrahim, J.K. and Burris, S. (2017), “Mapping medical marijuana: state laws regulating patients, product safety, supply chains and dispensaries, 2017", Addiction 112(12), 2206-2216. https://doi.org/10.1111/add.13910

Kilmer, B. and Smart, R. (2018), "How Will Cannabis Legalization Affect Alcohol Consumption?", The Rand Blog 13 February 2018. https://www.rand.org/blog/2018/02/how-will-cannabis-legalizationaffect-alcoholconsumption. Html

Klein, A. and Potter, G. (2018), "The three betrayals of the medical cannabis growing activist: from multiple victimhood to reconstruction, redemption and activism", International Journal of Drug Policy 53, 65-72. https://doi.org/10.1016/j.drugpo.2017.12.004

Lenton, S., Asmussen Frank, V., Barratt, M.J., Potter, G.R. and Decorte, T. (2018), “Growing practices and the use of chemical additives among a sample of small-scale cannabis growers in three countries", Drug and Alcohol Dependence 192, 250-256.

https://doi.org/10.1016/j.drugalcdep.2018.07.040

MacCoun, R.J. and Reuter, P. (2001), Drug war heresies: learning from other vices, times and places, Cambridge, Cambridge University Press

MacDonald, Z., Tinsley, L., Collingwood, J., Jamieson, P. and Pudney, S. (2005), Measuring the harm from illegal drugs using the drug harm index. Home Office, London.

http://www.homeoffice.gov.uk/rds/pdfs05/rdsolr2405.pdf

Manrique-Garcia, E., Zammit, S., Dalman, C., Hemmingsson, T., Andreasson, S. and Allebeck, P. (2012), "Cannabis, schizophrenia and other non-affective psychoses: 35 years of follow-up of a population-based cohort", Psychological Medicine 42(6), 1321-1328.

doi:10.1017/S0033291711002078

McCulloch, L. (2017), "Why did cannabis treatment presentations rise in England from 2004-2005 to 2013-2014?", Drugs and Alcohol Today 17(4), 218-231. https://doi.org/10.1108/DAT-08-2017-0033

Melberg, H.O., Jones, A.M. and Bretteville-Jensen, A.L. (2009), "Is cannabis a gateway to hard drugs?", Empirical Economics 38, 583-603. 
Moore, T.H.M., Zammit, S., Lingford-Hughes, A., Barnes, T.R.E., Jones, P.B., Burke, M. and Lewis, G. (2007), "Cannabis use and risk of psychotic or affective mental health outcomes: a systematic review", Lancet 370(9584), 319-328. https://doi.org/10.1016/S0140-6736(07)61162-3

Morgan, C.J., Schafer, G., Freeman, T.P. and Curran, H.V. (2010), "Impact of cannabidiol on the acute memory and psychotomimetic effects of smoked cannabis: naturalistic study", British Journal of Psychiatry 197(4), 285-290. doi:10.1192/bjp.bp.110.077503

Morgan, C.J. and Curran, H.V. (2008), "Effects of cannabidiol on schizophrenia-like symptoms in people who use cannabis", British Journal of Psychiatry 192(4), 306-307.

doi:10.1192/bjp.bp.107.046649

Murphy, M. (2016), "Police forces turn blind eye to weed in UK", Daily Star.

National Academies of Sciences, Engineering, and Medicine (2017), The health effects of cannabis and cannabinoids: The current state of evidence and recommendations for research, National Academies Press, Washington DC.

Nugent, S.M., Morasco, B.J., O’Neil, M.E., Freeman, M., Low, A., Kondo, K., ... Kansagra, D. (2017), "The effects of cannabis among adults with chronic pain and an Overview of general harms: a systematic review", Annals of Internal Medicine 167(5), 319-331. doi:10.7326/M17-0155

Nutt, D. (2014), “Medicinal cannabis: time for a comeback?" The Pharmaceutical Journal, 19 November 2014. https://pharmaceutical-journal.com/article/opinion/medicinal-cannabis-time-for-acomeback

Nutt, D.J., King, L.A. and Phillips, L.D. (2010), "Drug harms in the UK: a multicriteria decision analysis" The Lancet 376: 1558-1565. https://doi.org/10.1016/S0140-6736(10)61462-6

OFGEM (2014), Tackling electricity theft - the way forward. OFGEM, London.

ONS [Office for National Statistics] (2020), Drug misuse in England and Wales - appendix table. ONS, London.

https://www.ons.gov.uk/peoplepopulationandcommunity/crimeandjustice/datasets/drugmisuseine nglandandwalesappendixtable

Paoli, L., Decorte, T. and Kersten, L. (2015), "Assessing the harms of cannabis cultivation in Belgium", International Journal of Drug Policy, 26(3): 277-289. https://doi.org/10.1016/j.drugpo.2014.12.003

Parey, M. and Rasul, I. (2020), "Measuring the market size for cannabis: a new approach using forensic economics", Economica 88(350), 297-338. https://doi.org/10.1111/ecca.12354

Pedersen, W. and Skardhamar, T. (2010), "Cannabis and crime: findings from a longitudinal study", Addiction 105(1), 109-118. https://doi.org/10.1111/j.1360-0443.2009.02719.x

Potter, D.J., Hammond, K., Tuffnell, S., Walker, C. and Di Forti, M. (2018), "Potency of $\Delta 9-$ tetrahydrocannabinol and other cannabinoids in cannabis in England in 2016: Implications for public health and pharmacology." Drug Testing and Analysis 10(4): 628-635.

https://doi.org/10.1002/dta.2368

Potter, G.R. (2010), Weed, need and greed: a study of domestic cannabis cultivation. Free Association Books, London.

Potter, G.R., Barratt, M.J., Malm, A., Bouchard, M., Blok, T., Christensen, A-S., ... Wouters, M. (2015), "Global patterns of domestic cannabis cultivation: sample characteristics and patterns of growing 
across eleven countries". International Journal of Drug Policy 26(3), 226-237.

https://doi.org/10.1016/j.drugpo.2014.12.007

Potter, G.R. and Klein, A. (2020), "Coming out of the closet: risk management strategies of illegal cannabis growers". In S. MacGregor and B. Thom (Ed.s) Risk and substance use: framing dangerous people and dangerous places. Routledge, London.

Randerson, J. (2007), "Warning issued over cannabis adulterated with glass beads." The Guardian $12^{\text {th }}$ January 2007.

Ranganathan, M. and D'Souza, D.C. (2006), "The acute effects of cannabinoids on memory in humans: a review", Psychopharmacology 188, 425-444. https://doi.org/10.1007/s00213-006-0508-y

Reiman, A. (2009), "Cannabis as a substitute for alcohol and other drugs", Harm Reduction Journal 6, 35. doi:10.1186/1477-7517-6-35

Ribeiro, L.I. and Ind, P.W. (2016), "Effect of cannabis smoking on lung function and respiratory symptoms: a structured literature review", NPJ Primary Care Respiratory Medicine 26, 16071. doi: 10.1038/npjpcrm.2016.71

Ritter, A. (2009), "Methods for comparing drug policies-The utility of composite Drug Harm Indexes" International Journal of Drug Policy 20: 475-479.

https://doi.org/10.1016/j.drugpo.2009.02.012

RSA [The Royal Society for the encouragement of Arts, Manufactures \& Commerce] (2007), Drugs facing facts: the report of the RSA commission on illegal drugs, communities and public policy, London, RSA.

Russell, C., Rueda, S., Room, R., Tyndall, M. and Fischer, B. (2017), "Routes of administration for cannabis use - basic prevalence and related health outcomes: a scoping review and synthesis." International Journal of Drug Policy 52: 87-96. https://doi.org/10.1016/i.drugpo.2017.11.008

Runciman, R. (2000), Drugs and the Law: report of the independent inquiry into the misuse of drugs act 1971, London, The Police Foundation.

Sewell, R. A., Poling, J. and Sofuoglu, M. (2009), "The effect of cannabis compared with alcohol on driving", American Journal of Addiction 18(3), 185-193.

https://doi.org/10.1080/10550490902786934

Shiner, M., Carre, Z., Delsol, R. and Eastwood, N. (2018), The colour of injustice: 'race', drugs and law enforcement in England and Wales. StopWatch/LSE/Release, London.

Snowdon, C. (2018), Joint Venture: Estimating the size and potential of the UK Cannabis Market. Insitute of Economic Affairs, London.

Subritzky, T., Pettigrew, S. and Lenton, S., (2017), "Into the void: Regulating pesticide use in Colorado's commercial cannabis markets." International Journal of Drug Policy 42, 86-96. https://doi.org/10.1016/j.drugpo.2017.01.014

Transform, (2018), Cannabis Policy in the Netherlands: Moving forwards not backwards. Transform, London. 
Uhl, A. and Kraus, L. (2009), "Reassessing the gateway theory and its implications for drug policy". In Demetrovics, Z., Fountain, J. and Kraus, L. (Ed.s) Old and New Policies, Theories, Research Methods and Drug Users Across Europe. Pabst, Lengerich.

UNODC [United Nations Office on Drugs and Crime] (2021), World drug report 2021. UNODC, Vienna.

Volkow, N.D., Baler, R.D., Compton, W.M. and Weiss, S.R.B. (2014), "Adverse health effects of marijuana use", New England Journal of Medicine 370, 2219-2227. doi:10.1056/NEJMra1402309

Wouters, M. and Korf, D.J. (2009), "Access to licensed cannabis supply and the separation of markets policy in the Netherlands", Journal of Drug Issues 39(3), 627-651.

https://doi.org/10.1177/002204260903900308

Zimmer, L.E. and Morgan, J.P. (1997), Marijuana myths, marijuana facts: a review of the scientific evidence. Lindesmith Center, New York. 